\title{
AGR-1 Post-Irradiation Examination Test Requirements
}

\author{
Paul Demkowicz
}

December 2006

The INL is a U.S. Department of Energy National Laboratory operated by Battelle Energy Alliance 


\title{
AGR-1 Post-Irradiation Examination Test Requirements
}

\author{
Paul Demkowicz
}

December 2006

Idaho National Laboratory

Idaho Falls, Idaho 83415

Prepared for the

U.S. Department of Energy

Office of Nuclear Energy

Under DOE Idaho Operations Office

Contract DE-AC07-05ID14517 


\title{
AGR-1 Post-Irradiation Examination Test Requirements
}

\author{
INL/EXT-06-12051
}

December 2006

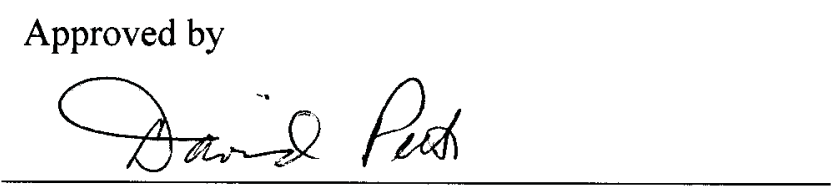

David Petti

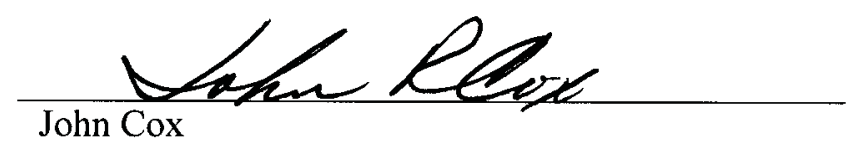

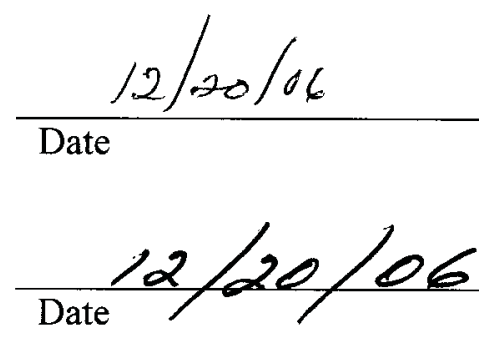




\section{SUMMARY}

As the first in a series of test irradiations for the NGNP Fuel Development and Qualification Program, the AGR-1 Irradiation Experiment is scheduled to begin irradiation in the Advanced Test Reactor in December 2006. At the conclusion of the experiment, the test train will be removed from the reactor and shipped to the Hot Fuel Examination Facility at the Materials and Fuels Complex at the INL for extensive post-irradiation examination. The PIE for this experiment will focus on:

1. Assessing the performance of the multicapsule instrumented test train and components;

2. Evaluating the fission product retention of the fuel during irradiation and during post-irradiation accident testing;

3. Characterizing the compacts and individual particles to observe the condition of the matrix material, kernels, and coatings and document any concerns.

This document presents a basic set of requirements for the post-irradiation examination of the AGR-1 test train and fuel. 



\section{CONTENTS}

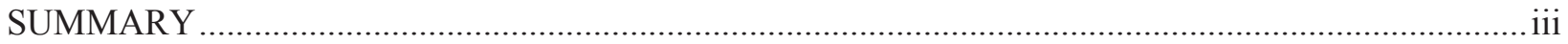

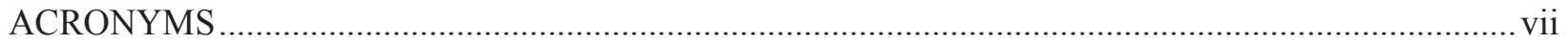

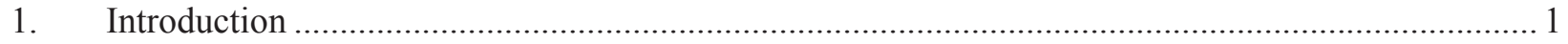

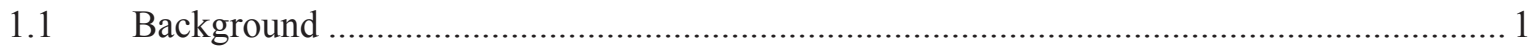

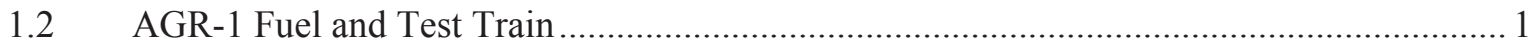

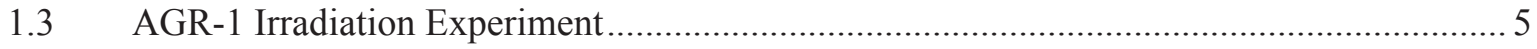

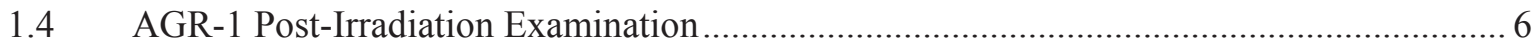

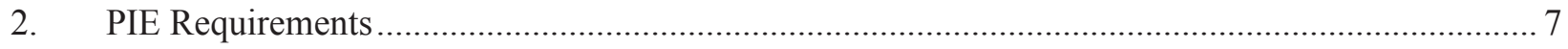

2.1 Test train inspection and disassembly ................................................................... 7

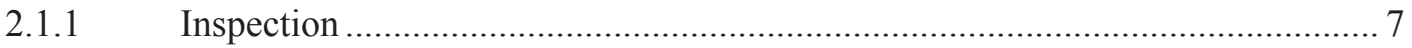

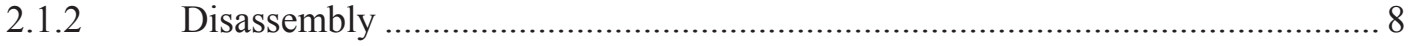

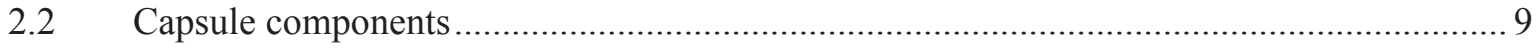

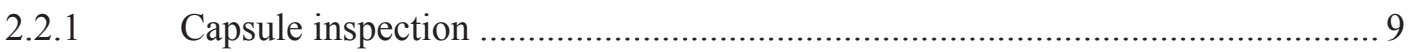

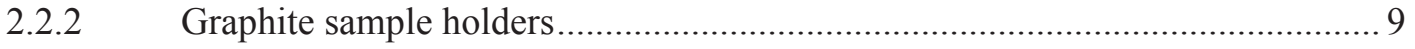

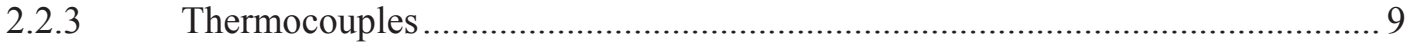

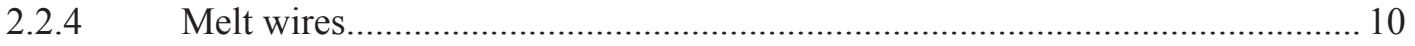

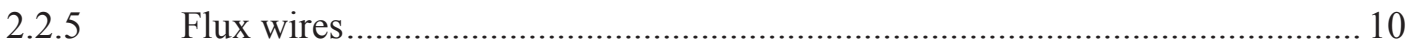

2.2.6 Fuel compact visual inspection, metrology, and properties ............................ 10

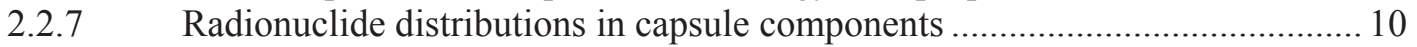

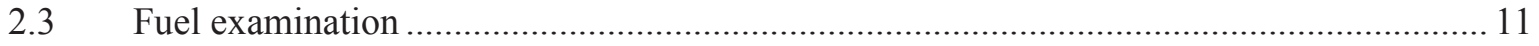

2.3.1 Fuel compact cross-section analysis ............................................................ 11

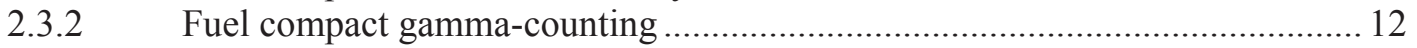

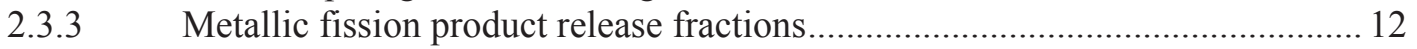

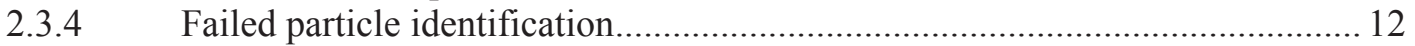

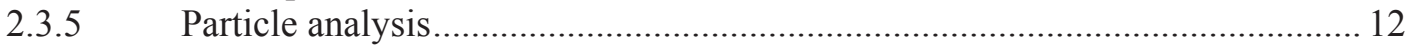

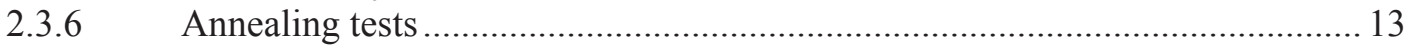

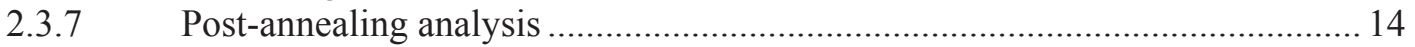

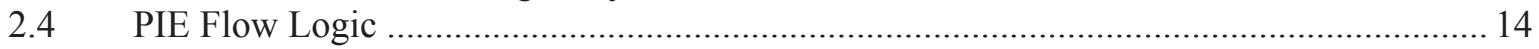

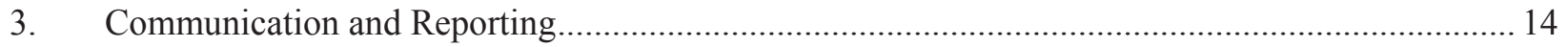

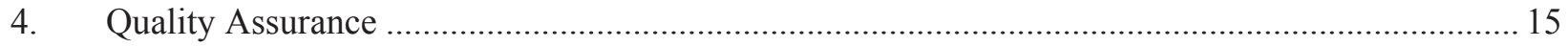

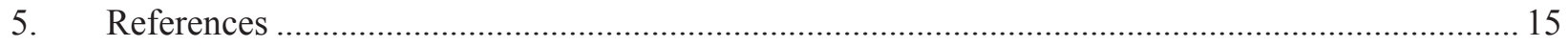

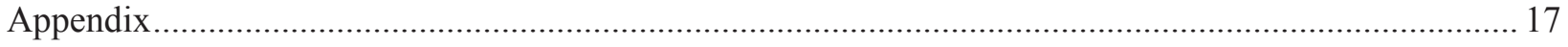




\section{FIGURES}

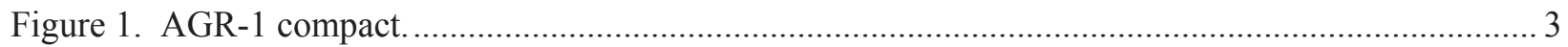

Figure 2. Radial cross-section schematic of an AGR-1 irradiation capsule (Maki 2006)......................... 4

Figure 3. A single assembled AGR-1 capsule showing the raised metal stand-offs on the exterior that indicate the location where the capsule should be sectioned during test train disassembly.............. 8

Figure 4. Example temperature profile for post-irradiation annealing test. ............................................ 14

\section{TABLES}

Table 1. Properties of baseline and variant particles used in AGR-1 experiment (Maki 2006)................ 2

Table 2. Capsule sequence in test train and fuel variant in each capsule................................................. 5 


\section{ACRONYMS}

$\begin{array}{ll}\text { AGR } & \text { Advanced Gas Reactor } \\ \text { ATR } & \text { Advanced Test Reactor } \\ \text { EFPD } & \text { Effective full power days } \\ \text { EPMA } & \text { Electron probe microanalysis } \\ \text { FIMA } & \text { Fissions per initial metal atom } \\ \text { HFEF } & \text { Hot Fuel Examination Facility } \\ \text { IMGA } & \text { Irradiated Microsphere Gamma Analysis } \\ \text { INL } & \text { Idaho National Laboratory } \\ \text { IPyC } & \text { Inner pyrocarbon } \\ \text { LBL } & \text { Leach-burn-leach } \\ \text { LEU } & \text { Low-enriched uranium } \\ \text { NGNP } & \text { Next Generation Nuclear Plant } \\ \text { NRAD } & \text { Neutron radiography } \\ \text { OPyC } & \text { Outer pyrocarbon } \\ \text { PIE } & \text { Post-irradiation examination } \\ \text { R/B } & \text { Release-to-birth ratio } \\ \text { SEM } & \text { Scanning electron microscopy } \\ \text { TC } & \text { Thermocouple } \\ \text { UCO } & \text { Uranium oxycarbide } \\ \text { VHTR } & \text { Very High Temperature Reactor }\end{array}$




\section{AGR-1 Post-Irradiation Examination Test Requirements}

\section{Introduction}

\subsection{Background}

The Next Generation Nuclear Plant (NGNP) Fuel Development and Qualification Program ${ }^{\mathrm{a}}$ was established to perform the requisite research and development on coated particle gas-reactor fuel to support deployment of a very high-temperature reactor (VHTR), which has been selected as the reactor concept for the NGNP project. The overarching goal of this program is to provide a baseline fuel qualification data set to support licensing and operation of a VHTR. To achieve these goals, the program includes fuel fabrication, irradiation, post-irradiation examination and safety testing, and fuel performance and fission product transport modeling activites.

Eight separate fuel irradiation experiments in the Advanced Test Reactor (ATR) at the Idaho National Laboratory (INL) are planned. These experiments are intended to provide data on fuel performance under irradiation, support fuel process development, qualify the fuel for normal operating conditions, provide irradiated fuel for safety testing, and support the development of fuel performance and fission product transport models. The first of these irradiation tests, AGR-1, is scheduled for insertion into ATR in early FY2007. This experiment is intended to act as a shakedown test of the multi-capsule design, as well as to provide early data on fuel performance that will be used in fuel fabrication process development. It is also expected that this test will provide samples for post-irradiation safety testing. The AGR-1 fuel, test train, and experiment description have been presented in the AGR-1 Test Plan (Maki 2006). The test objectives and success criteria have been discussed by Kendall (2006).

\subsection{AGR-1 Fuel and Test Train}

The kernels for the AGR-1 fuel are made of low-enriched uranium (LEU) oxycarbide (UCO). Kernel diameters are approximately $350 \mu \mathrm{m}$ with uranium-235 enrichment of approximately $19.7 \%$. The detailed characterization data of the kernel fabrication lot used in the AGR-1 fuel has been given in the Data Certification Package from BWXT (BWXT 2005). The kernels are coated successively with a porous carbon buffer ( $\sim 100 \mu \mathrm{m}$ thickness), an inner pyrolytic carbon (IPyC) layer ( $\sim 40 \mu \mathrm{m}$ thickness), a $\mathrm{SiC}$ layer ( $\sim 35 \mu \mathrm{m}$ thickness), and an outer pyrolytic carbon (OPyC) layer ( 40 $\mu \mathrm{m}$ thickness). The total fuel particle diameter is approximately 800 microns.

The AGR-1 irradiation experiment will include a baseline fuel as well as three different fuel variants (Maki 2006). Fuel variants each represent a particular deviation in the processing parameters of either the IPyC or $\mathrm{SiC}$ coating layers compared to the baseline fuel and are included in order to explore areas of uncertainty in the fuel processing/performance relationship. The specific changes in the coating deposition conditions are expected to result in differences in coating microstructures and density which could influence particle performance during irradiation. Selected properties of the baseline and variant fuel forms are given in Table 1 (selected data taken from Maki 2006). Detailed characterization data for the particle coatings of the baseline and variant fuel forms has been given previously (Hunn and Lowden, 2006a-2006d).

\footnotetext{
${ }^{a}$ Known previously as the Advanced Gas Reactor (AGR) Program
} 
Table 1. Properties of baseline and variant particles used in AGR-1 experiment (Maki 2006).

\begin{tabular}{|c|c|c|c|c|c|}
\hline \multirow[t]{2}{*}{ Property } & \multirow{2}{*}{$\begin{array}{l}\text { Specified } \\
\text { Range for } \\
\text { Mean } \\
\text { Value } \\
\end{array}$} & \multicolumn{4}{|c|}{ Actual Mean Value \pm Population Standard Deviation } \\
\hline & & Baseline & Variant 1 & Variant 2 & Variant 3 \\
\hline Buffer thickness $(\mu \mathrm{m})$ & $100 \pm 15$ & $103.5 \pm 8.2$ & $102.5 \pm 7.1$ & $102.9 \pm 7.3$ & $104.2 \pm 7.8$ \\
\hline IPyC thickness $(\mu \mathrm{m})$ & $40 \pm 4$ & $39.4 \pm 2.3$ & $40.5 \pm 2.4$ & $40.1 \pm 2.8$ & $38.8 \pm 2.1$ \\
\hline SiC thickness $(\mu \mathrm{m})$ & $35 \pm 3$ & $35.3 \pm 1.3$ & $35.7 \pm 1.2$ & $35.0 \pm 1.0$ & $35.9 \pm 2.1$ \\
\hline OPyC thickness $(\mu \mathrm{m})$ & $40 \pm 4$ & $41.0 \pm 2.1$ & $41.1 \pm 2.4$ & $39.8 \pm 2.1$ & $39.3 \pm 2.1$ \\
\hline $\begin{array}{l}\text { Buffer density } \\
\left(\mathrm{Mg} / \mathrm{m}^{3}\right)\end{array}$ & $0.95 \pm 0.15$ & $1.10 \pm 0.04$ & $1.10 \pm 0.04$ & $1.10 \pm 0.04$ & $1.10 \pm 0.04$ \\
\hline IPyC density $\left(\mathrm{Mg} / \mathrm{m}^{3}\right)$ & $1.90 \pm 0.05$ & $1.904 \pm 0.014$ & $1.853 \pm 0.012$ & $1.912 \pm 0.015$ & $1.904 \pm 0.013$ \\
\hline $\operatorname{SiC}$ density $\left(\mathrm{Mg} / \mathrm{m}^{3}\right)$ & $\geq 3.19$ & $3.208 \pm 0.003$ & $3.206 \pm 0.002$ & $3.207 \pm 0.002$ & $3.205 \pm 0.001$ \\
\hline OPyC density $\left(\mathrm{Mg} / \mathrm{m}^{3}\right)$ & $1.90 \pm 0.05$ & $1.907 \pm 0.008$ & $1.898 \pm 0.009$ & $1.901 \pm 0.008$ & $1.911 \pm 0.008$ \\
\hline $\begin{array}{l}\text { Sphericity } \\
\text { (aspect ratio) }\end{array}$ & $\begin{array}{l}\text { Mean not } \\
\text { specified }^{\text {(a) }}\end{array}$ & $1.054 \pm 0.019$ & $1.056 \pm 0.019$ & $1.053 \pm 0.019$ & $1.055 \pm 0.018$ \\
\hline $\begin{array}{l}\text { Particle diameter }{ }^{(b)} \\
(\mu \mathrm{m})\end{array}$ & $\begin{array}{l}\text { Mean not } \\
\text { specified }\end{array}$ & 799.7 & 804.0 & 798.3 & 795.1 \\
\hline Particle mass (g) & $\begin{array}{l}\text { Mean not } \\
\text { specified }\end{array}$ & $7.27 \times 10^{-4}$ & $7.33 \times 10^{-4}$ & $7.24 \times 10^{-4}$ & $7.26 \times 10^{-4}$ \\
\hline
\end{tabular}

Notes: (a) Critical region is specified such that $\leq 1 \%$ of the particles shall have an aspect ratio $\geq 1.14$.

(b) Based upon mean average particle measurements, not sums of mean layer thicknesses.

After fabrication the fuel particles are formed into right cylindrical compacts using a matrix composed of a thermosetting carbonaceous material. The compacts are nominally $12.3 \mathrm{~mm}$ in diameter and $25 \mathrm{~mm}$ long (Figure 1). Prior to compacting, the particles are overcoated with approximately $165 \mu \mathrm{m}$ of the matrix material to prevent particle-particle contact and achieve the desired volume fraction of fuel particles in the compact. Each compact was fabricated to have a fuel-free carbon end-cap $(\sim 1.5 \mathrm{~mm}$ thickness) on both the top and bottom to prevent damage to the embedded particles from contact during handling or irradiation. There are roughly 4,100 fuel particles in each compact. The total compact mass is roughly 5 grams with a mean uranium loading of approximately $0.9 \mathrm{~g}$ per compact. Detailed characterization data for the compacts has been given previously (Hunn et al., 2006a-200d) 


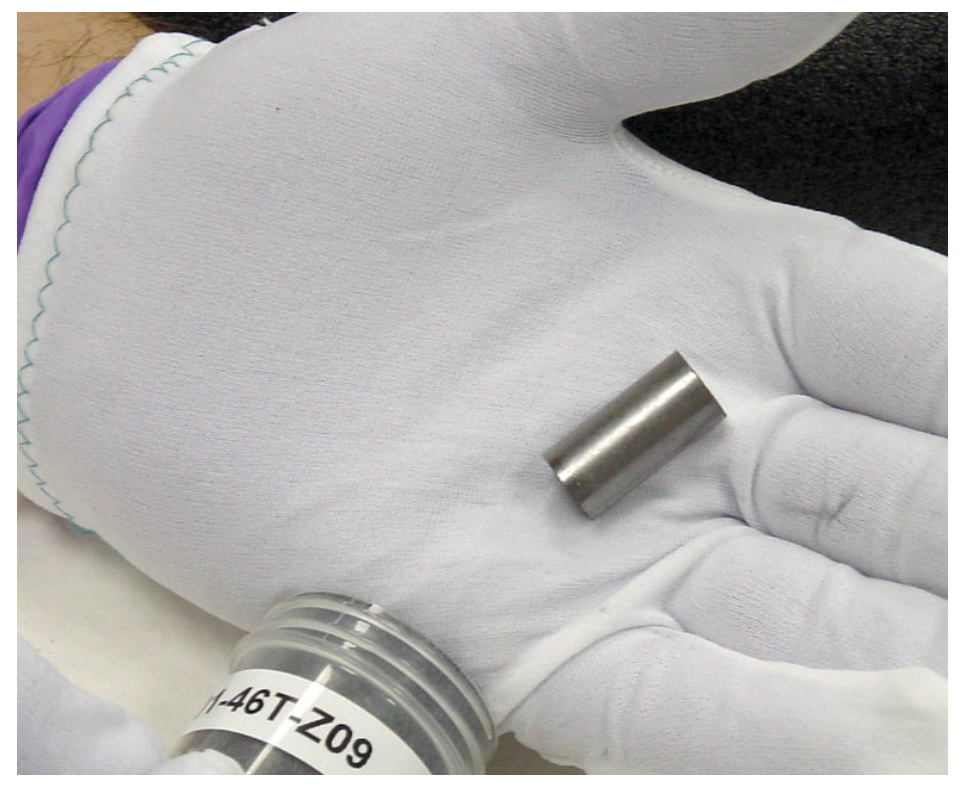

Figure 1. AGR-1 compact.

The AGR-1 test train consists of six irradiation capsules, each approximately $13 / 8$ " (35 mm) in diameter and 6" (152 $\mathrm{mm})$ long, and each containing a total of twelve fuel compacts in three stacks (Figure 2). The capsules consist of a graphite sample holder with holes machined for insertion of fuel compacts, thermocouples (TCs), encapsulated melt and flux wires, and molybdenum through-tubes to allow gas lines and TC leads to pass through to the other capsules in the test train. The graphite sample holders contain boron carbide $\left(\mathrm{B}_{4} \mathrm{C}\right)$ as a burnable poison to provide a more uniform particle power distribution throughout the experiment. The orientation of the compact stacks in the irradiation capsule places Stacks 1 and 3 closer to the reactor core than Stack 2 (see Figure 2), which would result in much higher neutron fluxes in Stacks 1 and 3. To counteract this effect, a combination of hafnium and stainless steel shrouds surround the graphite support to provide a more uniform neutron flux during the experiment. The entire assembly is encapsulated in a stainless steel cylinder. 


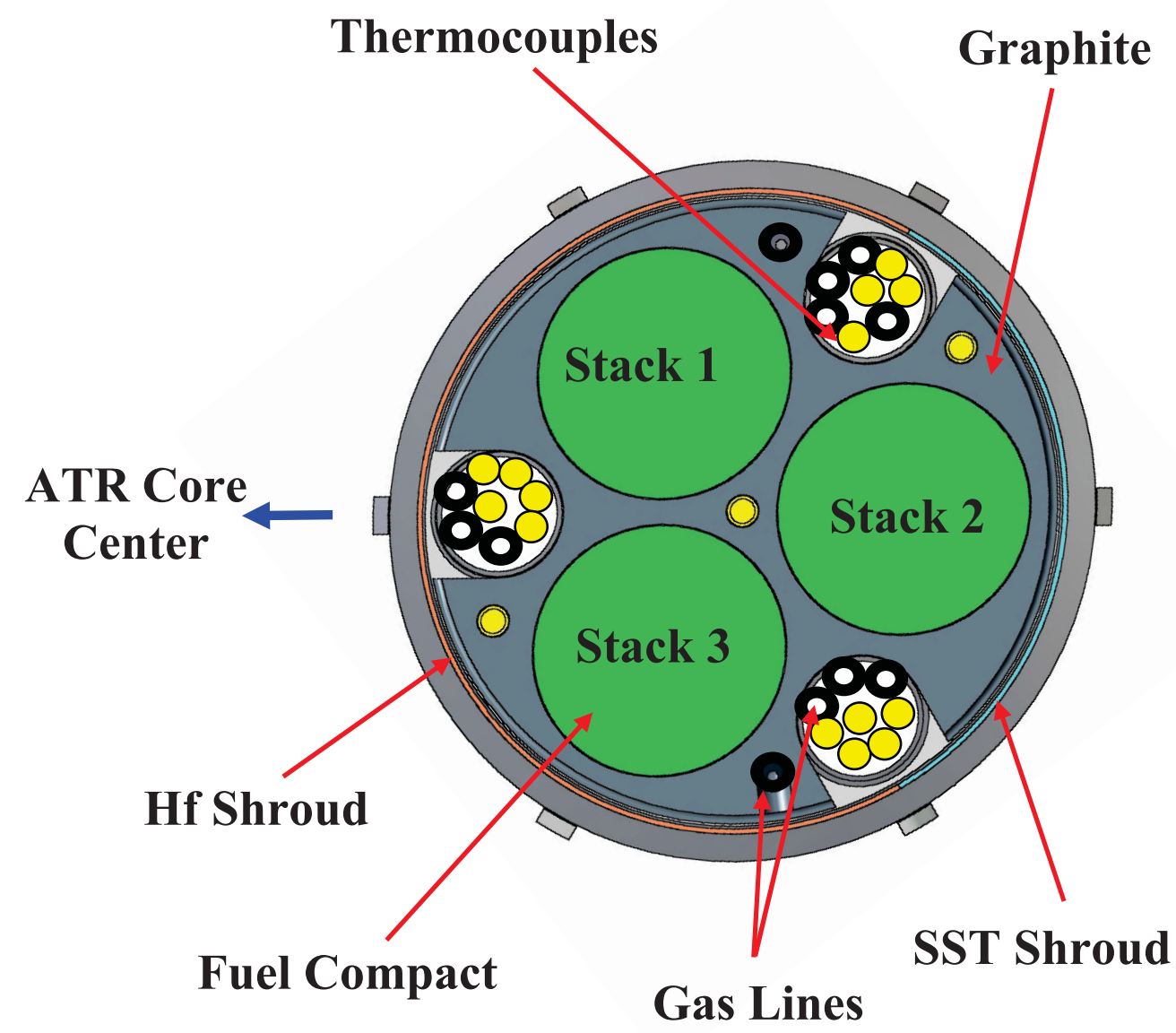

Figure 2. Radial cross-section schematic of an AGR-1 irradiation capsule (Maki 2006).

A total of six independent capsules are used in the AGR-1 test train, with each capsule containing only one type of fuel variant. The capsules are stacked end to end and welded together to form the fueled portion of the test train. The relative location of each capsule in the test train and the fuel variant in each are shown in Table 2. Each capsule is supplied with an inert sweep gas mixture of helium and neon. Because of the very different thermal conductivities of the gases, varying the gas mixture can act to manage the temperature in the capsule. The sweep gas from each capsule is routed to a detector that measures the quantity of fission gas present in the effluent from each capsule. This provides a means of monitoring the integrity of the fuel throughout the irradiation. In addition, He-3 gas can be used as the sweep gas mixture to limit power spikes that might occur during occasional high power cycles in the ATR, referred to as PALM cycles. The AGR-1 test train is described in further detail in the AGR-1 Test Plan (Maki 2006). 
Table 2. Capsule sequence in test train and fuel variant in each capsule.

\begin{tabular}{|c|c|}
\hline Capsule & Fuel variant \\
\hline Capsule 6 (top) & Baseline \\
\hline Capsule 5 & Variant 1 \\
\hline Capsule 4 & Variant 3 \\
\hline Capsule 3 & Baseline \\
\hline Capsule 2 & Variant 2 \\
\hline Capsule 1 (bottom) & Variant 3 \\
\hline
\end{tabular}

The TCs used in the test train are a combination of commercial Type $\mathrm{N}$ and experimental $\mathrm{Mo}-\mathrm{Nb}$ TCs fabricated and tested at INL. The TCs are inserted into holes drilled in the graphite sample holder at various locations. Capsules 2-5 will have three TCs each while the top capsule (capsule 6) will have five TCs and the bottom capsule (capsule 1) will have two TCs. The Mo- $\mathrm{Nb}$ TCs have $\mathrm{Nb}-0.1 \% \mathrm{Zr}$ sheaths, while the Type N TCs have either Inconel or molybdenum sheaths. Additional niobium sleeves are used to separate the Inconel sheaths from the graphite sample holder in order to avoid the possible migration of $\mathrm{Fe}, \mathrm{Cr}$, or $\mathrm{Ni}$ from the Inconel into the graphite, which could result in chemical reaction with the $\mathrm{SiC}$ particle coatings. It is difficult to predict the longevity of these TCs under the irradiation conditions expected in the AGR-1 test train. This is especially true of the Mo-Nb TCs, since these are experimental in nature. Therefore part of the post-irradiation examination of the test train and capsules will be to examine the TCs to the extent possible and determine failure modes, if necessary.

Each capsule will contain a vanadium-encapsulated pure beryllium melt wire in a hole drilled near the periphery of the graphite sample holder. The encapsulation is about $7.9 \mathrm{~mm}$ long and $1.3 \mathrm{~mm}$ in diameter and each will be engraved with a unique ID number. These will be used to indicate if the temperature of the capsule (at the location of the melt wire) exceeded $1287^{\circ} \mathrm{C}$. The capsules will also contain three different flux wires (pure $\mathrm{Fe}, \mathrm{V}-0.1 \% \mathrm{Co}$, and pure $\mathrm{Nb}$ ), each encapsulated in vanadium. The encapsulated wires will be placed in holes drilled in the graphite sample holder. The encapsulations are between 4.8 and $8.6 \mathrm{~mm}$ long and each will be engraved with a unique ID number. The measured activity in the wires after irradiation will be used to calculate the neutron fluence for the appropriate neutron energy range.

\subsection{AGR-1 Irradiation Experiment}

The AGR-1 test train will be irradiated in the B-10 position of the ATR at the INL. The irradiation test condition requirements for the AGR-1 experiment have been specified in the AGR-1 Test Specification (Maki 2004) and are listed below.

- The instantaneous peak temperature for each capsule shall be $\leq 1400^{\circ} \mathrm{C}$.

- The time average, peak temperature for each capsule shall be $\leq 1250^{\circ} \mathrm{C}$.

- The time average, volume average temperature for each capsule shall be $1150+30 /-75^{\circ} \mathrm{C}$.

- The minimum compact average burnup for each fuel compact shall be $>14 \%$ FIMA.

- The compact average burnup goal for the majority of the fuel compacts should be $>18 \%$ FIMA. 
- The maximum peak fast neutron fluence for each fuel compact shall be $<5 \times 10^{25} \mathrm{n} / \mathrm{m}^{2}, \mathrm{E}>0.18$ $\mathrm{MeV}$.

- The minimum peak fast neutron fluence for each fuel compact shall be $>1.5 \times 10^{25} \mathrm{n} / \mathrm{m}^{2}, \mathrm{E}>0.18$ $\mathrm{MeV}$.

- The instantaneous peak power per particle shall be $\leq 400 \mathrm{~mW} /$ particle.

Following irradiation, the TC and gas lines will be disconnected at the reactor vessel penetration flange. The gas lines will be capped and a cover installed on the test train leadout flange. The entire test train will then be lifted from the B-10 position and moved to the ATR canal. It is currently expected that the test train will cool in the canal for at least two months before it is packaged and transferred to the hot cell facility for disassembly and detailed post-irradiation examination (Maki 2006). The details of the test train transfer to the hot cell have not yet been determined.

\subsection{AGR-1 Post-Irradiation Examination}

The objectives of the AGR-1 test are (Kendall 2006, Petti et al. 2005):

1. Perform shakedown testing of the multi-capsule instrumented lead test train;

2. Provide early irradiation performance for baseline and variant fuel to help develop fundamental understanding of the relationship between fabrication processes, fuel properties, and irradiation performance;

3. Possibly support the selection of a reference fuel.

In accordance with these objectives for the irradiation experiment, the primary objectives of the post-irradiation examination will be to:

1. Assess the overall performance of the test train and components;

2. Evaluate the fission product retention of the fuel during the irradiation and during postirradiation accident tests;

3. Characterize the compacts and individual particles to document the condition of the matrix material, kernels, and coatings and document any concerns.

For this initial fuel irradiation experiment, the Program would like to demonstrate the following for at least one fuel variant:

i. Low in-reactor fission gas release (release-to-birth ratio $\leq 4 \times 10^{-6}$ ) as measured during irradiation by sweep gas analysis;

ii. Low release during irradiation (as measured during post-irradiation examination) of iodine and fission metals (e.g. ${ }^{110 \mathrm{~m}} \mathrm{Ag},{ }^{137} \mathrm{Cs},{ }^{154} \mathrm{Eu},{ }^{90} \mathrm{Sr}$ );

iii. Little or no kernel migration;

iv. Minimal corrosion and good structural integrity of the coatings;

v. Compact matrix stability and integrity;

vi. Minimal fission product release from fuel compacts under high temperature accident conditions (at least $1600^{\circ} \mathrm{C}$ in an inert gas atmosphere). 
These performance measures will provide confidence that the fuel fabrication has met the standards of high quality fuel, the UCO concept is controlling $\mathrm{CO}$ pressure buildup and the amoeba effect, and that the UCO-based fuel has satisfactory iodine and metallic fission product retention under accident conditions.

It is expected that the specific data required and the PIE tasks to be performed on the irradiated fuel will vary depending on the performance of the fuel during the irradiation, as indicated by measurements taken during the irradiation (e.g. fission gas release) and as the post-irradiation examination progresses. It is expected that high quality fuel will exhibit a low in-pile release-to-birth $(\mathrm{R} / \mathrm{B})$ ratio $\left(\leq 4 \times 10^{-6}\right)($ Kendall 2006). If the fuel performs at this level, it is expected that the fuel examination will focus primarily on high temperature accident testing. Higher fission gas releases during irradiation are indicative of higher particle failure fractions, and will require more extensive analysis of failed fuel compacts and particles in an attempt to identify the root causes of particle failures. Therefore the focus of the PIE task for the AGR-1 experiment may shift as in-reactor performance data becomes available.

This document will focus on basic data requirements for the irradiated fuel examination. Detailed descriptions of tasks and procedures to obtain these data will be documented in the AGR-1 PIE Test Plan that will follow this specification. Quantitative specifications on many of the PIE data needs and acceptance criteria are not yet established at this stage in the planning of the PIE experiments. The program must make decisions on these measures, and they will be included in a subsequent revision of this document.

A critical assumption in preparing this requirements document is that at least one of the capsules in the AGR-1 test train contains fuel that has met the in-pile requirements for fission gas retention and warrants post-irradiation safety testing.

\section{PIE Requirements}

\subsection{Test train inspection and disassembly}

\subsubsection{Inspection}

The exterior of the intact test train must be inspected to identify any significant damage or degradation. This should include an examination of the condition of the weld joints. Key regions of interest on the test train should be inspected under magnification. Photographs should be taken of the test train to document the overall condition and highlight any specific areas on the exterior surfacesincluding weld seams - that exhibit degradation or otherwise give cause for concern. Fine features of interest, such as the weld seams, should be photographed at a final magnification of at least 15X. Regardless of the technique used, high resolution digital image files should be produced for all photographs and micrographs.

The test train has been fabricated with raised metal stand-offs on the exterior that are used to center the test train in the experiment tube in the ATR core. These standoffs have been located at specific positions on the test train in order to be used to indicate where the individual capsules should be sectioned during disassembly (Figure 3). These are located between the capsule upper and lower welded metal caps and the main graphite sample holder that contains the fuel compacts. This space inside each capsule is occupied by graphite spacers. The post-irradiation condition of the graphite sample holder or the graphite spacers at each end of the capsule will not be known, and the possibility exists that these may have degraded during the irradiation and/or test train transport to the hot cell. Therefore either neutron radiography or gamma scanning should be used to verify that the pre-determined sectioning locations are 
still aligned properly with the interior capsule components and that there is no danger of cutting through fuel compacts during the test train disassembly operation. The data must indicate the relative locations of the capsule internal components relative to the exterior cutting guides. If necessary, the radiographs will be used to select new cutting locations as necessary to avoid destroying fuel compacts.

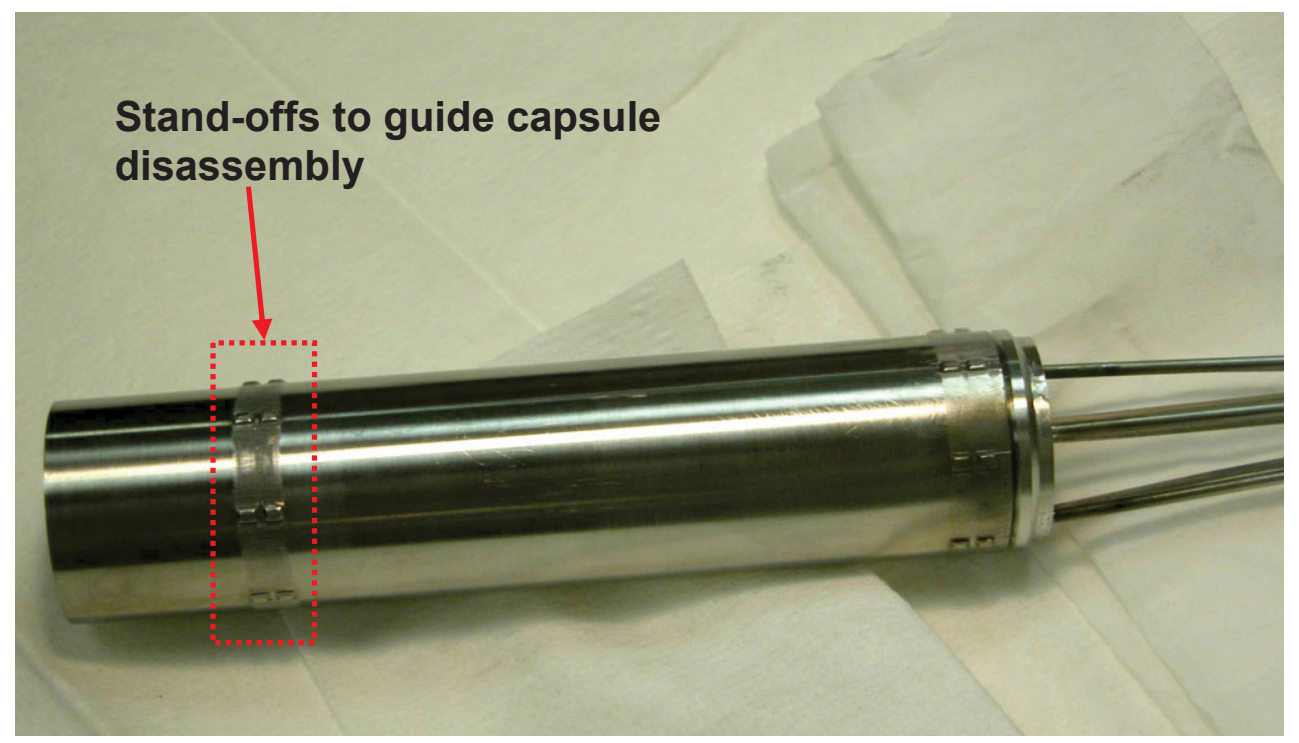

Figure 3. A single assembled AGR-1 capsule showing the raised metal stand-offs on the exterior that indicate the location where the capsule should be sectioned during test train disassembly.

\subsubsection{Disassembly}

Disassembly will involve sectioning the test train at the prescribed locations, with the goal of removing all of the individual capsule components for further analysis. These include:

1. Fuel compacts

2. Graphite sample holder

3. TC ends inside the graphite sample holder

4. Melt wire capsules

5. Flux wire capsules

6. Gas exit lines

7. Graphite and Grafoil® spacers

It is critical that all of the removed capsule components be cataloged so that the initial location in the capsule is preserved. This is particularly important with the fuel compacts: the capsule, level, and stack numbers should be recorded for each fuel compact.

The test train disassembly should be conducted so that as much of the gas exit lines as possible may be recovered intact and correlated to the capsule from which they originate. This will most likely require test train disassembly by turning the test train with an abrasive wheel instead of cutting through the entire cross-section with a saw. Turning the test train will allow each individual capsule to be 
separated from the others without severing the exit lines. Then identification of the exit line from each capsule will be possible as they will still be connected at the capsule top plate. This method, however, will require that the gas lines (supply and exit) as well as the TC leads be slid out of the through tubes, and there is some uncertainty as to how readily this will be achieved on the irradiated test train.

An additional requirement is that the test train and capsule disassembly must be performed in a manner that minimizes contamination of the components from the dust caused by cutting and grinding operations. Similarly, the transfer of in-cell contamination to the various components should also be minimized. The details of the disassembly procedure will be given in the AGR-1 PIE Plan.

\subsection{Capsule components}

\subsubsection{Capsule inspection}

The metallic capsule components, such as the top and bottom caps, gas lines, and braze joints should be visually inspected to identify any degradation such as evidence of chemical reactions between components, cracking, or failure of the braze joints. Photographs should be taken to document any areas or specific features of concern.

\subsubsection{Graphite sample holders}

The physical integrity of the graphite sample holders should be determined by visual examinations and documented with photography. The dimensions of the each graphite sample holder should be measured using an appropriate technique. The overall length, outer diameter, and inner diameter of the fuel compact holes should be determined with an uncertainty of $\leq 0.05 \mathrm{~mm}$. In addition, any deviations from uniformity in the diameters ("out-of-round") should be noted.

Thermal properties of the graphite sample holder are of interest in order to refine thermal calculations for the irradiation tests. Samples should be sectioned from the graphite sample holder and thermal properties measurements (including coefficient of thermal expansion and thermal conductivity) should be made using appropriate experimental techniques. The size and geometry of samples will be dictated by the analysis method and specific instrumentation.

\subsubsection{Thermocouples}

Pre-test performance predictions for the various TCs are highly speculative. Failure of one or more of the TCs during the course of the irradiation test is not unexpected. An important task for assessing the test train performance is an inspection of the TCs. During sectioning of the test train, the hot junction end of the TCs that is embedded in the graphite sample holders will be severed from the remainder of the test lead. This end of the TCs should be removed from the sample holder and radial cross-sections should be prepared for analysis using metallography and electron microscopy. The analysis should look for evidence of chemical interactions between the TC wires, insulation, sheath material, niobium sleeves (for Inconel sheathed TCs only), and the graphite sample holder, as well as physical damage (e.g. cracks) to the components. Another high priority item will be examination of the experimental TCs to assess their condition and determine causes of any failures. Causes of Type N TC failures are of a lower priority, as these TCs are largely expected to fail because the test conditions exceed the TC design specifications. 


\subsubsection{Melt wires}

All of the melt wire capsules must be examined to determine if local temperatures reached approximately $1287^{\circ} \mathrm{C}$ (the melting point of pure beryllium). This will involve opening the vanadium capsules and identifying either the presence of the Be wire or evidence of melting/solidification.

\subsubsection{Flux wires}

All of the flux wire capsules should be analyzed to determine the local fluence levels attained during the irradiation experiment.

\subsubsection{Fuel compact visual inspection, metrology, and properties}

Once removed from the capsule, the fuel compacts will be visually inspected for any damage, including cracks, spallation of portions of the compact, or other surface flaws. Each compact should be photographed at a magnification of approximately $10 \mathrm{X}$ to document the extent and location of sample degradation. Dimensional measurements of the compacts will include the length and diameter, and should be made with an uncertainty of $\leq 0.05 \mathrm{~mm}$. Diameter measurements should be made on at least three different axial locations. The primary objective of dimensional measurements is to document compact shrinkage or other dimensional aberrations that will be used to support performance and thermal modeling analyses.

Thermal properties of fuel compacts are also of interest in order to refine thermal calculations for the irradiation test and improve fuel performance models. This could be particularly important if the capsule TCs all fail during the irradiation, which would require the program to rely entirely on thermal modeling of the capsules to determine temperature histories. If it is experimentally feasible, measurements of the thermal expansion coefficient and thermal conductivity of the irradiated fuel compacts should be performed.

\subsubsection{Radionuclide distributions in capsule components}

The release of metallic fission products from fuel compacts during irradiation can be assessed by analyzing the surrounding components for deposited activity. The primary components of interest are the graphite sample holders and the metal capsules and through-tubes. It is expected that the majority of condensable fission products released from fuel compacts will reside in or on these components. These measurements should be as quantitative as experimentally feasible. Specific requirements are listed below for the individual capsule components.

\subsubsection{Graphite sample holders}

The distribution of fission products in the graphite sample holders should be determined in order to pinpoint the location of any hot spots that would indicate which compacts have released significant amounts of metallic fission products. A variety of methods could be employed for this purpose, including collimated gamma scans of the sample holders (with fuel compacts removed) in a manner that would isolate the individual fuel holes, or insertion of cylindrical films into the fuel holes.

Following the analysis, the total inventory of condensable fission products as well as actinides in the graphite sample holders should be determined quantitatively. 


\subsubsection{Metal capsule component analysis}

The metal capsules and through tubes should be analyzed to determine the quantity of fission metals and actinides that have been deposited on these surfaces. This can be accomplished by acid leaching the inside of the metal capsules and the exterior of the through tubes (i.e. the surfaces exposed to the graphite and fuel) and analyzing the leachates to quantify the removed material. This procedure should be performed as well on other incidental metallic components that are removed from the capsules.

\subsubsection{Gas exit line analysis}

The gas exit lines from each capsule should be analyzed to quantify condensable fission products that have plated out from the gas effluent stream. This can be accomplished by acid leaching and subsequent analysis of the leachates.

\subsection{Fuel examination}

The remaining data requirements for the fuel compacts (and subsequently, the individual fuel particles) are somewhat dependent on the performance of the fuel as determined by the measured $\mathrm{R} / \mathrm{B}$ ratios during the irradiation and in the fission product releases from the particles that are measured in the post-irradiation tests described in the following sections. Therefore the data needs are expected to develop as the PIE activities proceed. One of the primary objectives of the fuel examination is to determine if the fuel has met the target level of fission product retention during the irradiation and, if so, to determine if the fuel also meets the required level of fission product retention during high temperature accident testing. If the fuel fails either of these screening tests, the program may wish to expend resources to determine the cause(s) of the failures by identifying and examining failed particles. This type of analysis would require additional time and resources, the magnitude of which will be dependent on the number of fuel specimens that require the extended analysis. Therefore programmatic decisions will have to be made regarding prioritizing the PIE activities on the different fuel variants and how to proceed with the analysis. On the other hand, fuel that exhibits very poor fission product retention during the irradiation may be archived with very little post-irradiation characterization while the efforts of the program focus on fuel that performs well.

\subsubsection{Fuel compact cross-section analysis}

Micrographs will be obtained of polished compact cross-sections (either axial or radial). Because this task requires destruction of the compact, only a limited number of compacts from each capsule should be used for this. The sample distribution will be determined by the program and documented in the AGR-1 PIE Plan. The data required in compact cross-section analysis is an assessment of the condition of the compact matrix and individual particles. This includes microstructural flaws (e.g. cracks) in the graphite matrix, fuel kernel migration, condition of the buffer layer, corrosion of the SiC layer by fission products, cracks in the coating layers, and evidence of deleterious matrix-OPyC interactions. This will require, at a minimum, metallography of cross-sections at magnifications up to 1000X. Scanning electron microscopy and electron probe microanalysis of the irradiated compact cross-sections is desirable in order to highlight detailed structure in the kernels and coatings, and to identify fission product migration behavior both within particles and in the compact as a whole. 


\subsubsection{Fuel compact gamma-counting}

Selected fuel compacts will be gamma counted to determine bulk fission product inventories and to determine fuel burnup.

\subsubsection{Metallic fission product release fractions}

The release fractions of metallic fission products (e.g. ${ }^{110 \mathrm{~m}} \mathrm{Ag},{ }^{137} \mathrm{Cs},{ }^{154} \mathrm{Eu},{ }^{90} \mathrm{Sr}$ ) for the fuel compacts must be determined quantitatively. The task of measuring the inventory released from the compacts and deposited in or on the capsule components was discussed in Section 2.2.7. The quantity contained in the fuel matrix must now be measured using an appropriate technique.

In addition, measurement of the inventories of fission products in individual particles (by gamma scanning particles) can be used to determine release fractions. The individual particle analysis (i.e. Irradiated Microsphere Gamma Scanning) should be used to segregate particles into groups based on the release fractions observed for the various fission products to guide subsequent particle analysis. Undertaking this task requires that fuel compacts be first deconsolidated to liberate the fuel particles.

\subsubsection{Failed particle identification}

It is desirable to identify and retain individual failed particles. Analysis of fission product inventories of individual particles can be used to identify any particle failures which would be of great interest for subsequent analysis to help determine the cause of these failures. However, if the particle failure fractions are found to be very low (from in-pile data), the probability of locating individual failed particles will be low due to the relatively small number of particles in each capsule $(\sim 50,000)$. For example, if the in-pile failure fractions are $\sim 0.0001$, there would be on average five failed particles per capsule (i.e. less than on particle, on average, per compact), and locating these would be problematic. On the other hand, if in-pile failure fractions are found to be relatively high, the location of failed particles will have a higher probability.

In either case, it is helpful to have a means of identifying which specific compacts have failed particles (note that in-pile R/B data is averaged over the entire capsule). Some data toward this end may be gleaned from the fission product distributions in the graphite bodies (see Section 2.2.7). In addition, annealing tests (see Section 2.3.6) should be used to screen individual compacts to determine qualitatively which specimens contain particle failures. Compacts heated to reactor operating temperatures (approx.1100-1250 ${ }^{\circ} \mathrm{C}$ ) will be expected to release higher levels of fission gases if they contain failed particles compared to compacts containing no failures.

\subsubsection{Particle analysis}

The analysis of individual particles is intended to examine particle microstructures, document kernel migration, identify the extent of fission product migration through the coating layers, identify fission product interactions with the $\mathrm{SiC}$ coating, identify through-coating cracks, and ultimately identify the cause of coating failures (where applicable). Scanning electron microscopy and electron probe microanalysis of polished particle cross-sections are required to analyze microstructures and elemental composition distributions in the particle. Since these methods involve analysis of a single plane through the particle - overlooking the majority of the particle/coating volume-multiple grindings/polishings of the sample particle should be used to look at multiple planes through a single particle. Of particular interest in the micrographic analysis of coating layers is the microstructure of the silicon carbide layers, which is believed to have a significant effect on the diffusion of metallic species. 
Three-dimensional tomography of the particles to enable analysis of the condition of the entire spherical coatings would represent a significant improvement over the two-dimensional analyses provided by electron microscopy. Techniques should be investigated to perform this type of particle analysis.

\subsubsection{Annealing tests}

Fuel that has exhibited low R/B ratios during irradiation and good retention of metallic fission products in post-irradiation examinations will be subjected to post-irradiation annealing tests to verify fission product retention during high temperature accident scenarios. The samples are to be heated in an inert gas, and the release of metallic fission products and fission gases should be measured as a function of annealing time. The inert atmosphere will be maintained at a pressure of approximately 1 bar during heating experiments. The primary fission products of interest are: ${ }^{85} \mathrm{Kr},{ }^{110 \mathrm{~m}} \mathrm{Ag},{ }^{131} \mathrm{I},{ }^{134} \mathrm{Cs},{ }^{137} \mathrm{Cs},{ }^{154} \mathrm{Eu}$, and ${ }^{90} \mathrm{Sr}$.

Note that analysis of ${ }^{131}$ I will require compact re-irradiation and relatively rapid initiation of annealing tests due to the $\sim 8$ day half life. The re-irradiation conditions should be controlled so that the additional incremental burnup is less than $0.2 \%$ FIMA and that the heat generated in the particle is minimized to prevent propagation of thermally driven effects in the particles (i.e. fission product migration, coating corrosion).

The heating profile of each test should include, at a minimum: a soak at a temperature sufficient to eliminate moisture from the system, a ramp to prototypical reactor operating temperatures $(\sim 1100$ $\left.1250^{\circ} \mathrm{C}\right)$ and hold to reach equilibrium, and a ramp to accident temperatures $\left(\sim 1600-1800^{\circ} \mathrm{C}\right)$. An example of an annealing test temperature profile is shown in Figure 4. The duration of the hold times at the final target temperature will be somewhat dependent on fuel performance, but should be sufficient to reach a plateau in fission product release (usually on the order of several hundred hours). The temperature of the fuel during annealing must be controlled to within $\pm 1 \%$ of the target value.

The method of measuring metallic fission product releases should result in sufficient data points over the duration of a test to produce relatively smooth release profiles (typically at least $\sim 20$ measurements during a test). The measurement of inert fission gases should be continuous during the experiment. 


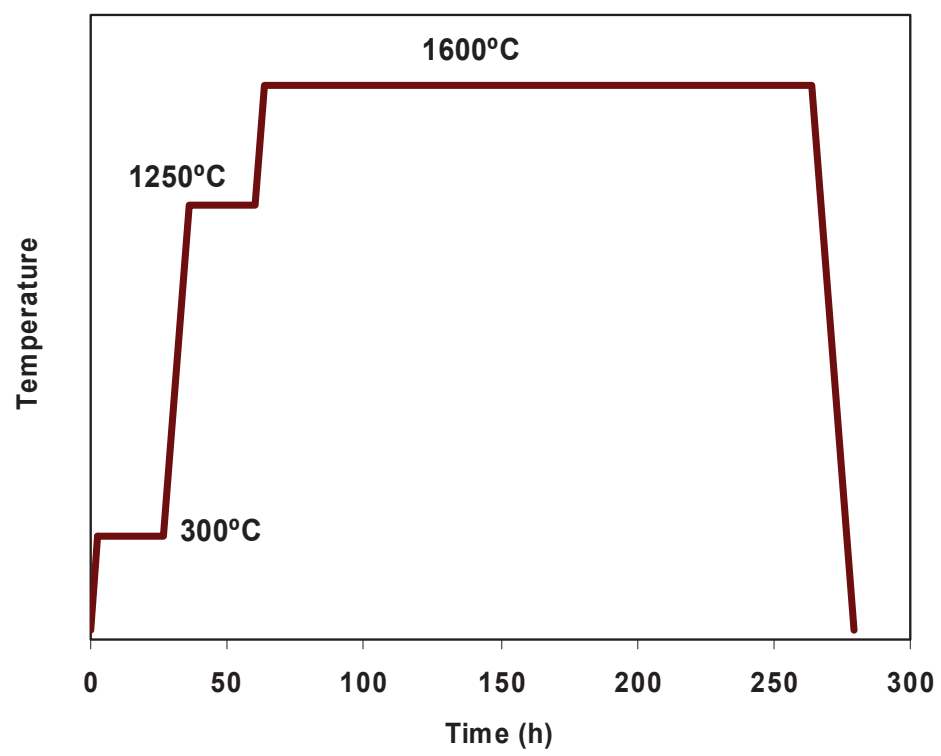

Figure 4. Example temperature profile for post-irradiation annealing test.

\subsubsection{Post-annealing analysis}

Following an annealing test, each compact may be selected for additional specific analyses based on the test results. Metallography should be performed on selected compacts for comparison with the pre-anneal metallography (Section 2.3.1). Selected compacts should be deconsolidated and the particles analyzed with SEM/EPMA to observe the effects of high temperature annealing on the coatings and fission product migration. Compacts that have exhibited high fission product release fractions during the annealing tests should be deconsolidated and the particles gamma scanned so that failed particles can be specifically identified for microscopic analysis. The analysis of individual failed particles would be subject to requirements similar to those outlined in Section 2.3.5, with the objective of identifying particle failure modes. Intact particles should also be examined with SEM/EPMA to determine their integrity and observe any degradation that could be indicative of incipient failure.

\subsection{PIE Flow Logic}

The general proposed PIE flow logic is given in the Appendix. This is intended to conceptualize the order that PIE activities will follow and the important decisions that will guide subsequent analyses. A detailed breakdown of tasks, as well as the inclusion of a plan for distributing sample and activities between the two participating laboratories, will be given in the AGR-1 PIE Plan.

\section{Communication and Reporting}

Technical leads and engineers (as appropriate) from all laboratories involved in the PIE activities will hold weekly conference calls to discuss progress, schedule, and any concerns. The PIE technical leads will also participate and provide input to the weekly AGR teleconferences. 
A description of activities and results of the AGR-1 PIE task will be documented in the following formats:

1. Monthly reports. These will be prepared at the end of each month and constitute the contribution of this program element to the AGR Program monthly report.

2. Annual reports. A report will be prepared at the end of each fiscal year in which AGR-1 PIE activities take place. These will summarize the current progress of the entire AGR-1 PIE effort.

3. Final report. A final report will be prepared at the completion of the AGR-1 PIE activities, presenting a summary of activities, experimental results and discussion, and important implications for future AGR fuel development and testing activities.

The PIE task participants will also provide input as required for NGNP program reports.

\section{Quality Assurance}

Work will be performed under the control of an INL Quality Assurance Program Plan or Project Execution Plan that identifies specific quality requirements that supports the post irradiation evaluation and data collection process.

\section{References}

BWXT Nuclear Products Division, 2005, G73 Industrial Fuel Fabrication and Development Lot G73D20-69302, Data Certification Package, March 11, 2005.

Hunn, J.D., and R. A. Lowden, 2006a, Data Compilation for AGR-1 Baseline Coated Particle Composite LEU01-46T, ORNL/TM-2006/019, April 2006.

Hunn, J.D., and R. A. Lowden, 2006b, Data Compilation for AGR-1 Variant 1 Coated Particle Composite LEU01-47T, ORNL/TM-2006/020, April 2006.

Hunn, J.D., and R. A. Lowden, 2006c, Data Compilation for AGR-1 Variant 2 Coated Particle Composite LEU01-48T, ORNL/TM-2006/021, May 2006.

Hunn, J.D., and R. A. Lowden, 2006d, Data Compilation for AGR-1 Variant 3 Coated Particle Composite LEU01-49T, ORNL/TM-2006/022, May 2006.

Hunn, J.D., F.C. Montgomery and P.J. Pappano, 2006a, "Data Compilation for AGR-1 Baseline Compact Lot LEU01-46T-Z, ORNL/TM-2006/507, August 2006.

Hunn, J.D., F.C. Montgomery and P.J. Pappano, 2006b, Data Compilation for AGR-1 Variant 1 Compact Lot LEU01-47T-Z, ORNL/TM-2006/508, August 2006.

Hunn, J.D., F.C. Montgomery and P.J. Pappano, 2006c, Data Compilation for AGR-1 Variant 2 Compact Lot LEU01-48T-Z, ORNL/TM-2006/509, August 2006.

Hunn, J.D., F.C. Montgomery and P.J. Pappano, 2006d, Data Compilation for AGR-1 Variant 3 Compact Lot LEU01-49T-Z, ORNL/TM-2006/510, August 2006. 
Kendall, James M., 2006, The AGR-1 Irradiation - Objectives, Success Criteria and Risk Management, INL/EXT-06-11487, June 2006

Maki, John T., 2006, AGR-1 Irradiation Experiment Test Plan, Rev. 1, INL/EXT-05-00593, September 2006

Maki, John T., 2004, AGR-1 Irradiation Test Specification, EDF-4731 Rev. 1, July 2004

Petti, David, Richard Hobbins, James Kendall, and John Saurwein, 2005, Technical Program Plan for the Advanced Gas Reactor Fuel Development and Qualification Program, INL/EXT-05-00465, August 2005 


\section{Appendix}

The proposed PIE flow logic is given in Figure A-1. This is intended to conceptualize the order that PIE activities will follow and the important decisions that will guide subsequent analyses. Four basic paths are included based on the in-pile fuel performance and PIE results. These are:

1. Fuel fails the in-pile fission gas release criteria (i.e. $\mathrm{R} / \mathrm{B} \leq 4 \times 10^{-6}$ )

2. Fuel passes the in-pile $\mathrm{R} / \mathrm{B}$ criteria but exhibits unacceptable fission metal retention.

3. Fuel passes the in-pile R/B criteria and has acceptable level of fission metal retention, but exhibits high release fractions in accident testing.

4. Fuel passes the in-pile R/B criteria and has acceptable level of fission metal retention and exhibits low release fractions in accident annealing tests.

It is expected that the approach to fuel examination will be slightly different for these four paths. Note that this chart does not include any information on how activities will be divided between the participating laboratories. This detail will be added in the AGR-1 PIE Plan. 


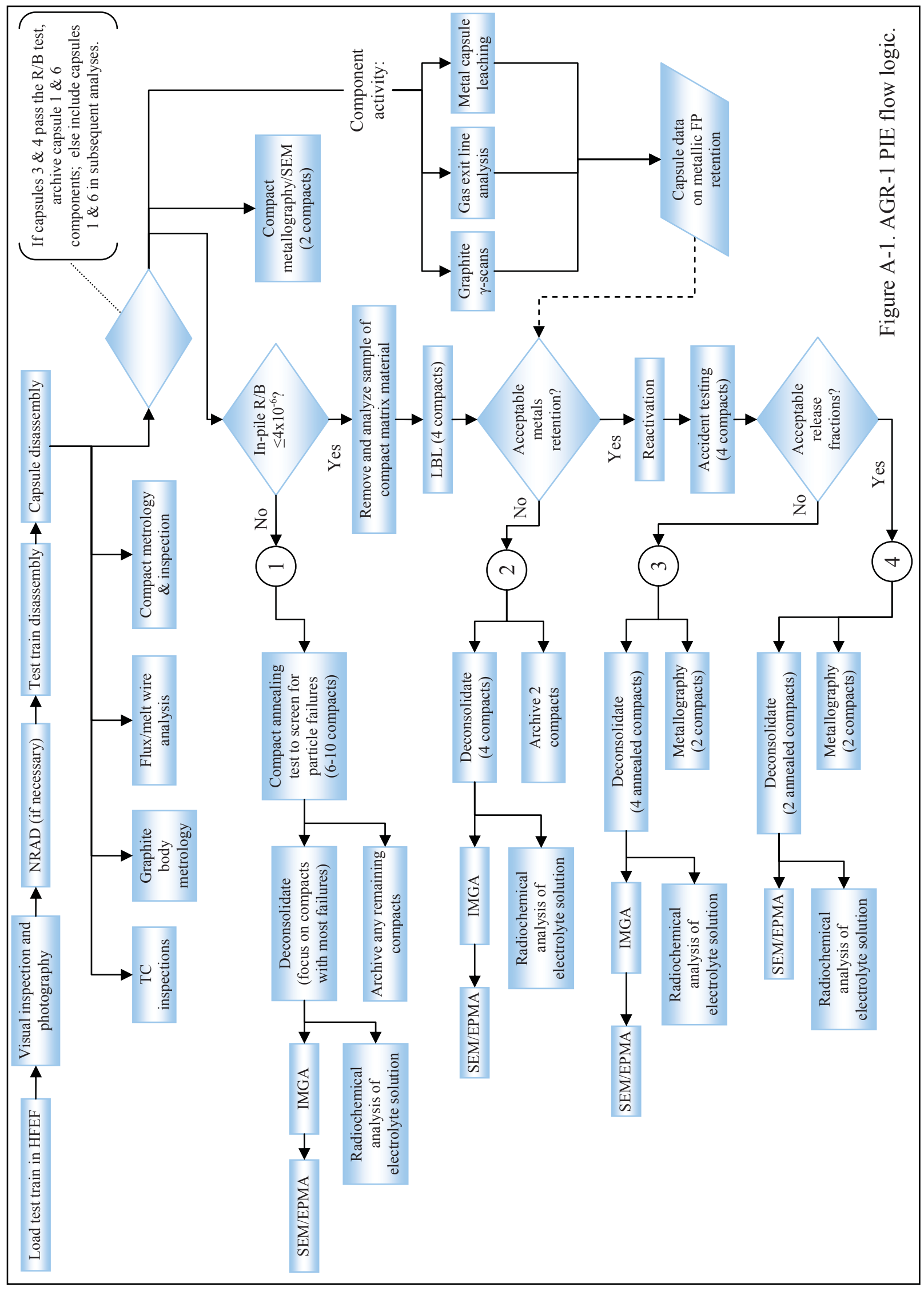

